This inhibition would be expected to inhibit viral DNA synthesis and thus to end viral replication. But we found that 42-nm ("infective virus") particles did not disappear from the blood during treatment, presumably because, although virus replication was inhibited, the clearance rate of the circulating particles was relatively slow in relation to the duration of treatment. Similarly, $\mathrm{HBe}$ antigen, a marker for the presence of infective virus, did not disappear from the blood during treatment. The slow clearance of viral particles was similar to that observed after inhibition of virus-specific DNA polymerase by human leucocyte interferon treatment in chronic hepatitis. ${ }^{12}$ In these studies the serum titre of $\mathrm{HBe}$ fell several weeks after the fall in DNA polymerase activity, and not until then did $\mathrm{HBs} A \mathrm{~g}$ titres fall. The results of vidarabine treatment were also similar to those of interferon in that DNA polymerase activity increased after treatment was stopped. Nevertheless, in the case of interferon continued treatment produced a sustained effect, and vidarabine will probably do the same.

The advantage of vidarabine is ease of synthesis, so that sufficient quantities could be made at low cost for treating the many HBsAg carriers throughout the world. This is in contrast to interferon, which is difficult to prepare, costly, and so in short supply. Whether inhibition of viral replication by vidarabine will permanently clear $\mathrm{HBsAg}$ and so arrest chronic liver disease remains to be determined. At the least this form of treatment may, by reducing the concentration of circulating virus particles, reduce the infectivity of the patient, thereby restricting the spread of the infection. Furthermore, its effectiveness may be enhanced, and hence duration of treatment reduced, by the concurrent use of immunostimulants which accelerate the clearance of existing infected cells, ${ }^{13}$ while vidarabine prevents further viral replication.

We gratefully acknowledge the support of the Sembal Trust and the gift of vidarabine from Warner-Lambert/Parke-Davis Pharmaceutical Research Division, Pontypool, Gwent, UK.

Dr M F Bassendine is supported by the Royal College of Physicians.

\section{References}

${ }^{1}$ Shannon, W M, in Adenine Arabinoside: An Antiviral Agent, ed D PavanLangston, B A Buchanan, and C A Alford, jun. New York, Raven Press, 1975.

2 Keenay, R E, in Adenine Arabinoside: An Antiviral Agent, ed D PavanLangston, B A Buchanan, and C A Alford, jun. New York, Raven Press, 1975.

${ }^{3}$ Steele, R W, et al, in Adenine Arabinoside: An Antiviral Agent, ed D Pavan-Langston, B A Buchanan, and C A Alford, jun. New York, Raven Press, 1975.

${ }^{4}$ Zarn, Z S, Centifanto, Y M, and Kaufman, H E, Antimicrobial Agents and Chemotherapy, 1974, 14, 139

${ }^{5}$ Kurtz, S M, in Adenine Arabinoside: An Antiviral Agent, ed D PavanLangston, B A Buchanan, and C A Alford, jun. New York, Raven Press, 1975.

${ }^{6}$ Hindman, S H, et al, Annals of Internal Medicine, 1976, 85, 458.

7 Alter, H J, et al, New England Fournal of Medicine, 1976, 295, 909.

${ }^{8}$ Eleftheriou, N, et al, Lancet, 1975, 2, 1171.

9 De Groote, J, et al, Lancet, 1968, 2, 626.

${ }^{10}$ Magnius, L O, and Espmark, J A, fournal of Immunology, 1972, 109, 1017

11 Robinson, W S, American fournal of Medical Science, 1975, 270, 151.

${ }_{12}$ Greenberg, H B, et al, New England fournal of Medicine, 1976, 295517.

${ }^{13}$ Chadwick, R G, et al, Gut, 1977, 18, A979.

(Accepted 16.June 1978)

\title{
Haemostatic defect in non-immune patients with falciparum malaria: no evidence of diffuse intravascular coagulation
}

J VREEKEN, TH MLCREMER-GOOTE

\section{Introduction}

After diffuse intravascular coagulation (DIC) had been accepted as a clinical entity disorders of haemostasis in severe malaria (especially falciparum malaria) were often recorded as being due to DIC, ${ }^{1-9}$ although some investigators disputed this. ${ }^{10-12}$ Furthermore, whereas some workers advocate the use of heparin in such cases, $2+51314$ others do not. ${ }^{1015-18}$

The past few years have seen an increasing number of nonimmune patients who do not or only irregularly take prophylactic antimalarial drugs. Thus the disease may be imported in nearly all parts of the world. This gave us the opportunity to study non-immune patients with falciparum malaria outside the tropics to see whether they had evidence of DIC.

One difficulty in evaluating reports on the possibility of DIC in malaria is the lack of generally accepted criteria for diagnosing DIC. Some workers base the diagnosis on the presence of two or more of the following: decreased platelet count, raised concentrations of fibrinogen or fibrin degradation products (FDP), and decreased concentrations of fibrinogen or other clotting factors. We considered the possibility of DIC when evidence of all the following were present: activation of the clotting mechanism (presence of circulating fibrin monomers), activation of the fibrinolytic system (raised FDP concentrations), consump-
Department of Internal Medicine, University Hospital "Wilhelmina Gasthuis," Amsterdam, the Netherlands

J VREEKEN, MD, professor of medicine

TH M CREMER-GOOTE, medical technician 
tion of platelets, and consumption of substrate clotting factors (fibrinogen and factor $\mathrm{V}$ ).

\section{Patients and methods}

During 1972-7 nine non-immune patients with falciparum malaria were admitted to this hospital 2-13 days after the onset of symptoms. All had omitted to take or had taken only irregularly their prophylactic antimalarial drugs while visiting tropical Africa. Two had cerebral malaria and four kidney damage, which in one case required haemodialysis. Patients were treated with either intravenous quinine (500$1500 \mathrm{mg} /$ day) or oral chloroquine (total dose $2100 \mathrm{mg}$ chloroquine base). While comatose, those with cerebral malaria were given $25 \mathrm{mg}$ prednisone four times a day intravenously. Heparin was not used. Laboratory studies included serial measurements of blood urea, serum creatinine, serum aspartate transaminase (serum AST; SGOT), serum alanine transaminase (serum ALT; SGPT), serum alkaline phosphatase, haemoglobin, leucocyte counts, platelet count, fibrinogen, ${ }^{19}$ and fibrinogen-fibrin degradation products (FDP) ${ }^{20}$; ethanol gelation tests for circulating fibrin monomers ${ }^{21}$; and assays for factor V. ${ }^{22}$

\section{Results}

All patients recovered without residual symptoms. One was comatose for four days after admission. Another became comatose for two days, six days after the onset of symptoms. Four patients had transient renal failure (serum creatinine concentrations 180-930 $\mu \mathrm{mol} / 1 ; 2 \cdot 0-10.5 \mathrm{mg} / 100 \mathrm{ml}$ (normal range $75-110 \mu \mathrm{mol} / 1 ; 0 \cdot 8-1 \cdot 2 \mathrm{mg} /$ $100 \mathrm{ml})$ ), which in one necessitated repeated haemodialysis. At discharge serum creatinine concentrations were normal or near normal in all patients.

Transient liver damage (serum ALT 20-90 IU/1 (normal <20 IU/1)) was observed in six patients. The haemoglobin concentration was normal in all patients admitted within 10 days after onset of symptoms. Over the next four days the concentrations fell in four patients to 6.4-8.0 $\mathrm{g} / \mathrm{dl}$, necessitating repeated blood transfusions in two.
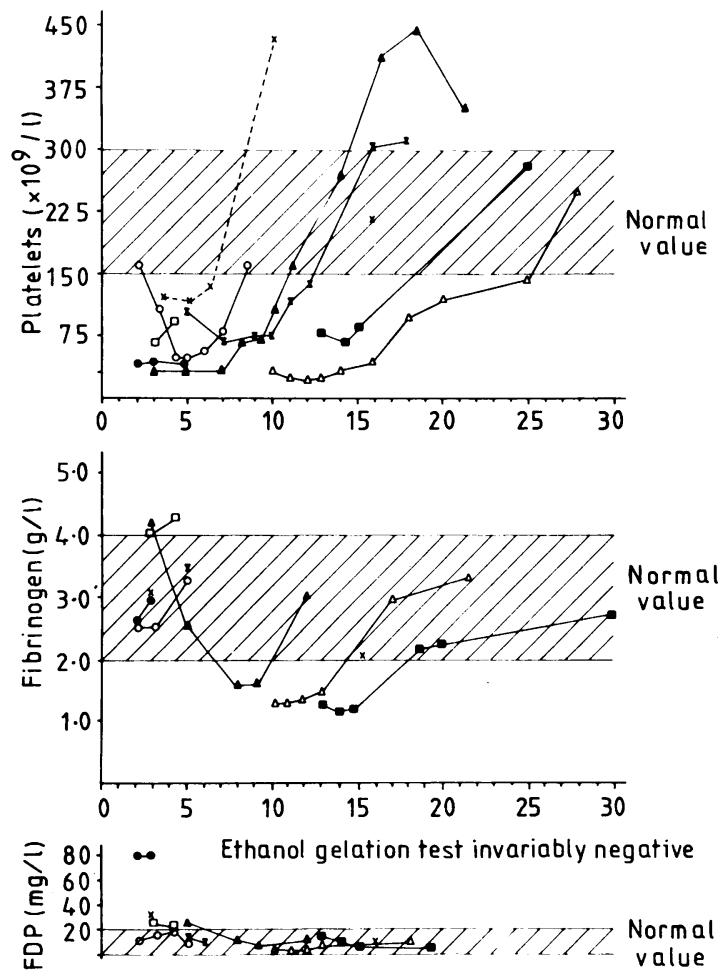

$$
\begin{array}{lllllll}
\hline 0 & 5 & 10 & 15 & 20 & 25 & 30 \\
\text { Days after onset of symptoms }
\end{array}
$$

FIG 1-Results of blood coagulation studies in nine patients with falciparum malaria.

\section{BLOOD COAGULATION STUDIES}

The frequency of haemostatic studies in each case varied with the severity of the symptoms and degree of abnormality of the results. All patients had thrombocytopenia initially (fig 1). One patient who was admitted on day 2 with a normal platelet count developed thrombocytopenia shortly afterwards. Since thrombocytopenia was present irrespective of the severity of the disease there appeared to be no relation between platelet count and clinical outcome. Thrombocytopenia was occasionally transient and could easily be missed. Some of the patients had a rebound thrombocytosis. In no case was the thrombocytopenia accompanied by bleeding symptoms. All patients admitted before day 5 after the onset of symptoms had normal plasma fibrinogen concentrations (fig 1). In one of these patients, admitted

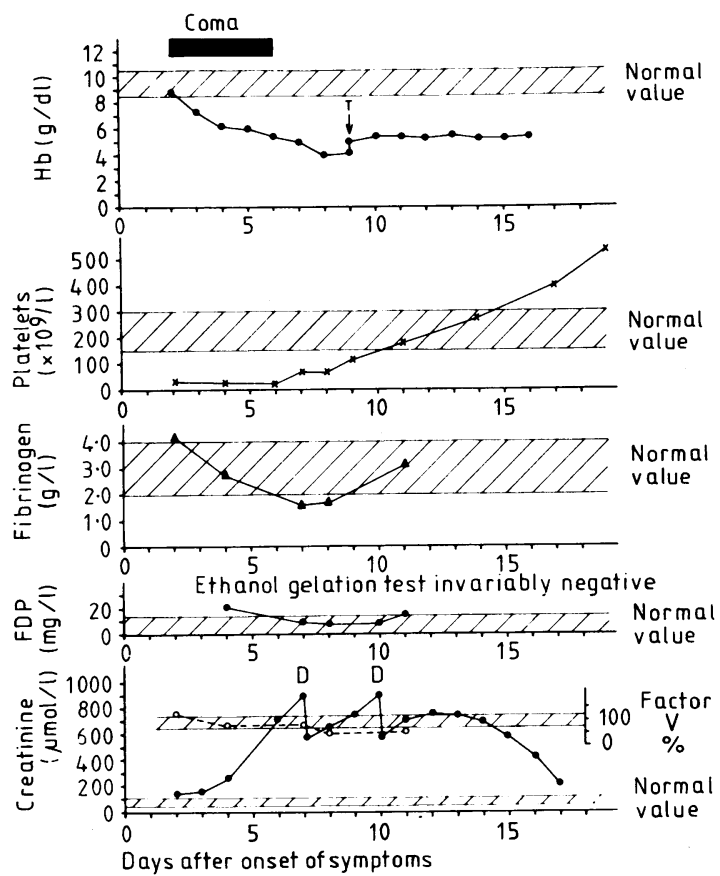

FIG 2-Haematological values during clinical course of patient with severe falciparum malaria. $T=$ Blood transfusion. $\mathrm{D}=$ Haemodialysis.

on day 3, the concentration then declined until the eighth day. Low concentrations were recorded in two patients admitted on the 10th and 13th days after the onset of symptoms. All patients with low fibrinogen concentrations had a complicated clinical course (increase in serum creatinine or coma or both). The fall in plasma fibrinogen concentrations occurred invariably after the onset of thrombocytopenia; thus there appeared to be no relation between the two.

Circulating fibrin monomers were never detected, even when the plasma fibrinogen concentrations were falling or patients had severe complications. Although more sensitive tests are available, circulating fibrin monomers would certainly have been detected had the rapid decline in fibrinogen concentrations observed in some of our patients been due to DIC. Plasma fibrinogen concentrations were never low enough to cause false-negative results. ${ }^{23}$

High FDP concentrations were found in only three patients (fig 1). In two these occurred soon after the onset of the disease. These patients had a benign and uncomplicated clinical course. FDP concentrations were never increased when plasma fibrinogen concentrations were low or falling.

Factor $\mathrm{V}$ concentrations were normal on admission in all patients except one, whose value was increased to $250 \%$. A patient, who had severe malaria (fig 2), was comatose for four days and twice received haemodialysis for kidney failure. Nevertheless, fibrin monomers were never detected in his circulation. Only once did he show a borderline increase in FDP. His thrombocytopenia occurred before the decline in fibrinogen concentration. Factor $\mathrm{V}$ was only slightly low $(70 \%$ on the eighth day). He could not be regarded as a patient with DIC. He recovered without heparin treatment. 


\section{Discussion}

Using our criteria for evidence of DIC in patients with falciparum malaria-namely, the presence of circulating fibrin monomers together with increased FDP concentrations, reduced platelet count, and low concentrations of fibrinogen and factor $\mathrm{V}$ -we found none of our patients to have DIC, including those with cerebral malaria and signs of kidney damage (fig 2). Thus we never gave heparin as additional treatment. All the patients survived without residual symptoms. In all cases the initial fall in platelet count preceded the decline in fibrinogen concentrations and appeared to be unrelated to the clinical outcome. Thrombocytopenia was sometimes transient and could easily be missed with infrequent determinations. In not any case was it followed by a bleeding diathesis at the time of thrombocytopenia. Thrombocytopenia is common in severe sepsis and is a normal occurrence during clearance of macromolecular particles from the blood stream ${ }^{24} 2 . ;$; we therefore regard it as a normal physiological phenomenon due to the clearance of parasites and red cell fragments from the blood and not as a special complication of the disease.

The fall in fibrinogen concentrations occurred invariably after the onset of thrombocytopenia (fig 1), though was not a constant finding. It is correlated with organ damage and can therefore be taken as a definite complication of the disease. In our patients it was not accompanied by systemic activation of fibrinolysis or by circulating fibrin monomers (the fibrinogen concentrations were high enough to rule out false-negative results ${ }^{23}$ ).

If the fall in fibrinogen concentrations cannot be attributed to DIC then what could be the cause ? A defect in synthesis by the liver seemed to be highly improbable in our patients, for other factors produced by the liver (factor V) showed hardly any decrease. Possibly the influence of infected red cells severely reduces the normal flow in the microcirculation in some organs and results in local fibrin formation. But this does not give rise to circulating fibrin monomers and to an enhanced FDP concentration, as would be the case in DIC. Perhaps all the fibrin monomers formed remain in the microcirculation and locally activated fibrinolysis is readily exhausted. If the existence of fibrin formation in the microcirculation of organs were proved it should be so described, and not as DIC. The fall in fibrinogen could also be caused by adsorption of fibrinogen to altered cell membranes in the microcirculation or to leakage of fibrinogen from the diseased microcirculation.

Since there was no evidence of DIC in our patients and the effect of heparin on falling fibrinogen concentrations is unknown we did not give heparin. The use of heparin should probably be contemplated only when clear-cut DIC, perhaps non-existent in falciparum malaria, had been demonstrated. Even then one must be aware that defects in other clotting factors may be concomitant due to acquired liver function disturbance. In our opinion, therefore, heparinisation is rarely called for in patients with severe falciparum malaria.

We are indebted to Professor P J Zuidema, Dr R M van der Heide, and $\operatorname{Dr} \mathrm{J} M$ Wilmink for help in treating these patients.

\section{References}

${ }^{1}$ McKay, D G, Disseminated Intravascular Coagulation, p 30. New York, Evanston, and London, Hoeber Medical Division, Harper and Row, 1965.

${ }^{2}$ Punyagupta, S, et al, American fournal of Tropical Medicine and Hygiene, $1974,23,551$.

${ }^{3}$ Devakul, K, Harinasuta, T, and Reid, H A, Lancet, 1966, 2, 886.

4 Dennis, L H, et'al, Blood, 1967, 29, 713.

5 Borochowitz, D, Crosley, A L, and Metz, J, British Medical fournal, 1970, 2, 710 .

6 Jaroonvesama, N, Lancet, 1972, 1, 221.

7 Paar, D, et al, British Medical fournal, 1970, 4, 805

${ }^{8}$ Meyer-Breiting, E, and Zimmerman, H, Zentralblatt für allgemeine Pathologie und pathologische Anatomie, 1975, 119, 286

${ }^{9}$ Bourdais, A, et al, Médicine et Armées, 1976, 4, 737.

10 Butler, T, et al, American fournal of the Medical Sciences, 1973, 265, 63.

11 Skudowitz, R B, et al, British Medical fournal, 1973, 2, 515.

12 Neva, F A, et al, Annals of Internal Medicine, 1970, 73, 295.

13 Smitskamp, H, and Wolthuis, F H, British Medical fournal, 1971, 1, 714.

14 Conrad, M E, Annals of Internal Medicine, 1969, 70, 134.

15 Reid, H A, Lancet, 1975, 1, 167.

16 Areekul, S, Fournal of the Medical Association of Thailand, 1972, 55, 389.

17 Jaroonvesama, N, et al, fournal of Tropical Medicine and Public Health, $1975,6,419$.

${ }^{18}$ Hall, A P, British Medical fournal, 1976, 1, 323.

19 Strengers, T, and Asberg, E G M, Nederlandsch Tijdschrift voor Geneeskunde, 1963, 107, 2044.

20 Bouma, B N, Scandinavian fournal of Haematology, 1971, suppl No 13, p 391.

${ }^{21}$ Godal, H C, and Abildgaard, U, Scandinavian fournal of Haematology, $1966,3,342$.

22 Stormorken, H, Scandinavian fournal of Clinical and Laboratory Investigation, 1957, 9, 273.

${ }^{23}$ Gerritis, W B J, et al, Thrombosis et Diathesis Haemorrhagica, 1974, 31, 299.

${ }^{24}$ Van Aken, W G, Goote, T M, and Vreeken, J, Scandinavian fournal of Haematology, 1968, 5, 333.

${ }^{25}$ Van Aken, W G, and Vreeken, J, Thrombosis et Diathesis Haemorrhagica, $1969,22,496$.

(Accepted 16 fune 1978)
ONE HUNDRED YEARS AGO We desire to call attention to the subjoined Statement of the circumstances, under which a militiasurgeon of large service has been reduced to absolute destitution by the harsh operation of the recent changes in the militia system, by which he-an officer of twenty-four years' standing-has without any compensation been suddenly and wholly deprived of the means of living. As this gentleman, who is beyond middle life, is desirous of employment, we shall be glad to receive any communications offering or suggesting such employment, as well as more direct aid:

"I am a Surgeon-Major in the Militia Medical Department and an MD of Edinburgh, attached to the - Militia, to which regiment I have been Surgeon for the last twenty-four years. During that period, I have performed all the medical military duty at Reading, including the medical inspection of recruits both for the line and militia. I have served abroad, and in every embodiment of my regiment, away from the head-quarters. In support of my efficiency as a military medical officer, I obtained, during the time of my service, the official thanks of Dr Andrew Smith, when Director-General of the Army Medical Department. I also hold a flattering testimonial from the late Sir James Gibson, Director-General, in reference to the same. As a doctor of medicine, and apart from my position in the Militia Medical Service, I hold very high professional and social testimonials.

"In going abroad with my regiment, in 1855, I gave up a good practice; and, in 1876, lost a Civil appointment of $£ 500$ per annum by accompanying my regiment to Gloucestershire; yet, when the new
Depot Centre System came into force, the emoluments of my appointment as Militia Surgeon, amounting to never less, and sometimes more, than $£ 250$ per annum, were taken from me-the duties hitherto performed by me, for so many years, being relegated to a surgeonmajor in the regular service; whilst I, a married man, without private means, am thrown upon the world to make a livelihood as I best can, at an age when it is impossible for a medical man to obtain one, without money to invest in the purchase of a practice. But, what makes the hardship of my case still more oppressive is the fact that the loss of my income from the militia has compelled me to relinquish the small private practice I had succeeded in making, amounting to little more than $£ 100$ per annum (I hold written orders from my commanding officer, prohibiting me, when in the receipt of full-pay, from engaging in private practice), which in itself was, of course, not sufficient to support the necessary expenditure in carrying it on, and I am completely ruined.

"I have made repeated applications to the Government for compensation, and pointed out Lord Cranbrook's statement in the House of Commons, when Secretary of State for War, to the effect 'that, whenever possible, employment would be given to militia surgeons deprived of their incomes by Lord Cardwell's Depot Centre System'; but all to no avail; and I hold a communication from the Horse Guards, dated December 19th, 1878, informing me 'that no employment connected with the Medical Department, either of the army of militia, could be offered me." " (British Medical fournal, 1878.) 